ORIGINAL RESEARCH ARTICLE

\title{
Factors Associated with Teen Pregnancy in sub-Saharan Africa: A Multi-Country Cross-Sectional Study
}

\author{
Clifford Odimegwu and Sibusiso Mkwananzi*
}

Demography and Population Studies Programme, Schools of Public Health and Social Sciences, University of the Witwatersrand, Johannesburg, South Africa

*For Correspondence: Email: Sibusiso.Mkwananzi@wits.ac.za; Phone: +27741818618

\begin{abstract}
This study aimed to assess the contextual factors associated with teenage pregnancy in sub-Saharan Africa. Using DHS data we modelled females aged 15-19 with multilevel logistic regression to establish the independent influence of social disadvantage on teenage pregnancy in West, East and Southern Africa with aid of the MLwiN programme. Results showed teenage pregnancy decreased in East Africa, plateaued in West Africa and increased slightly in Southern Africa between 1992 and 2011. Multilevel multivariate regression revealed teenage pregnancy was associated with family disruption $(0.39 ; 0.40$ : $\mathrm{P}<0.05)$, community-levels of female unemployment $(1.01 ; 0.99$ : $\mathrm{P}<0.05)$ and community poverty $(1.01 ; 1.02: \mathrm{P}<0.05)$ in Southern and East Africa, while only community poverty $(1.01 ; \mathrm{P}<0.05)$ independently predicted the outcome in West Africa. Our findings emphasise the necessity of creating regional-specific interventions and prevention campaigns to address multilevel factors such as family disruption as well as the need for governments to address issues of unemployment, poverty and inequality. (Afr J Reprod Health 2016 (Special Edition);20[3]: 94-107).
\end{abstract}

Keywords: Teenage pregnancy, sub-Saharan Africa, multilevel modelling, family disruption, poverty, unemployment

\section{Résumé}

Cette étude visait à évaluer les facteurs contextuels associés à la grossesse chez les adolescentes en Afrique sub-saharienne. En nous servons des données EDS, nous avons modélisé les femmes âgées de 15-19 ans avec la régression logistique multiniveaux pour établir l'influence indépendante de désavantage social sur la grossesse chez les adolescentes de l'Afrique : de l'Ouest, de l'Est et de l'Afrique du Sud à l'aide du programme MLwiN. Les résultats ont montré que la grossesse chez les adolescentes a diminué en Afrique Orientale, a atteint un palier en Afrique Occidentale et a légèrement augmenté en Afrique du Sud entre 1992 et 2011. La régression multivariée à plusieurs niveaux a révélé que la grossesse chez les adolescentes a été associé à une perturbation de la famille $(0,39 ; 0,40$ : $\mathrm{P}<0,05)$, les niveaux communautaires du chômage au féminin $(1,01 ; 0,99$ : $\mathrm{P}<0,05)$ et la pauvreté de la communauté $(1.01 ; 1.02: \mathrm{P}<0,05)$ en Afrique australe et orientale, tandis que la pauvreté communautaire $(1,01 ; \mathrm{P}$ $<0,05)$ a prédit indépendamment le résultat en Afrique de l'Ouest. Nos résultats soulignent la nécessité de créer des interventions spécifiques régionales et des campagnes de prévention pour traiter les facteurs à plusieurs niveaux tels que la perturbation de la famille, ainsi que la nécessité pour les gouvernements de résoudre les problèmes du chômage, de la pauvreté et de l'inégalité. (Afr J Reprod Health 2016 (Edition Spéciale); 20[3]: 94-107).

Mots clés: grossesse adolescente, Afrique sub-saharienne, modélisation niveaux multiples, perturbation de la famille, pauvreté, chômage

\section{Introduction}

Teenage pregnancy remains a challenge requiring urgent resolution the world over ${ }^{1}$. In 2014 the World Health Organization reported that $11 \%$ of all births were due to women aged 15-19 years, an estimated 16 million women globally ${ }^{2}$. Approximately $95 \%$ of teenage pregnancies happen in developing countries with 36.4 million women becoming mothers before age 18 and 5.6 million having a live birth before age 15 in $2010^{1}$. Sub-Saharan Africa had the highest prevalence of teenage pregnancy in the world in $2013^{1}$. Births to teenage mothers account for more than half of all the births in this region: an estimated 101 births per 1000 women aged 15 to 19 . This is almost double the global average ${ }^{1,3}$. Fourteen of the fifteen countries worldwide that had more than $30 \%$ of $20-24$ year olds giving birth before age 18 are in sub-Saharan Africa and include Niger, Mozambique, Malawi, Uganda and Cameroon ${ }^{4}$.

Consequences of teenage pregnancy are numerous encompassing obstetric, health, economic and social problems. Firstly, teenage 
mothers are at higher risk of obstetric complications such as: incontinence from obstetric fistulae, eclampsia, post-partum haemorrhage, sepsis and a five-fold increased risk of maternal mortality ${ }^{2,5-7}$. Additionally, disadvantageous prospects exist for the teenage mother, including lower educational attainment and school dropout resulting in lower income-earning potential and perpetuation of poverty ${ }^{8}$. Secondly, the children that teenagers bear experience higher levels of birth complications, poor health outcomes and deprivation ${ }^{9-11}$. Therefore, curbing teenage pregnancy has become an urgent health and social matter, particularly in sub-Saharan Africa.

To address the challenge of teenage pregnancy, national governments and nongovernmental organisations (NGOs) have adopted various strategies that target adolescents. Numerous governments have also refined their policies since the 1994 international conference on population and development (ICPD). This has mainly involved the advocating of abstinence before marriage, keeping girls in school beyond primary school, preventing early marriage and coerced sex as well as increasing the use of contraceptives as encouraged by the World Health Organisation guidelines of 2011 on preventing early pregnancy ${ }^{12}$. In Kenya, intervention programmes training teachers in HIV and providing education subsidies for girls resulted in a slight reduction of teenage pregnancy and dropout levels ${ }^{13}$. Moreover, some African countries have attempted an integrated approach to sexual health promotion among young people where sexually transmitted infection, HIV and pregnancy prevention information and services are provided together ${ }^{14}$. For example, in Madagascar provision and mass awareness of youth-friendly clinics was implemented since 2001. These clinics ensured inexpensive and confidential access to contraceptives as well as diagnosis and treatment of sexually transmitted infections and counselling for sexual and reproductive health concerns. Additionally, Cameroon undertook peer education to empower youth on issues such as dating, peerpressure, sexuality as well as prevention of pregnancy and disease ${ }^{14}$.

However, despite these efforts, teenage pregnancy continues to reach crisis proportions in many African countries collectively representing the highest proportion of the phenomenon globally ${ }^{4}$. Such rates are a regional concern. Evaluations of prevention programmes are few and have shown mixed results ${ }^{13,14}$. Additionally, most interventions have not considered the influence of the social context in which young people are in that may impact on their behaviour thereby preventing the reduction of teenage pregnancy. This is highly urgent as teenage pregnancy in the sub-continent has led to subSaharan African countries not meeting numerous millennium development goals surrounding education, fertility and maternal mortality. Therefore, if we are to meet the newly established sustainable development goals associated with gender equity, education, health and wellbeing it is of extreme importance to address teenage pregnancy timeously in the sub-continent ${ }^{15}$.

Recent studies on teenage pregnancy in subSaharan Africa have looked at individual level demographic, socio-economic and reproductive health knowledge and behaviour parameters ${ }^{16-28}$. This research has identified education and socioeconomic status as consistent determinants of teenage pregnancy. Other studies have explored the effect of household variables on teenage pregnancy in Nigeria, Kenya, and Lesotho and showed household size and parents' marital status as household predictors of teenage pregnancy ${ }^{18,29-}$ 32. Nevertheless, previous studies have failed to comprehensively investigate factors beyond the individual level.

Disparities in teenage pregnancy based on location exist in sub-Saharan Africa. In 2013, birth rates ranged from 150 or higher to less than 50 births per 1000 women of ages 15 to 19 in the subcontinent, with Central Africa displaying the highest levels and Southern Africa having the lowest ${ }^{3}$. These vast disparities in birth rates among teenagers across the sub-continent indicate that factors beyond the individual level may possibly influence teenage pregnancy. Previous studies on teenage pregnancy by Mkhwanazi (2010), Jewkes et al. (2009) and Panday et al. (2009) have recommended the need to study the social factors leading to teenage pregnancy due to cultural views, the dynamics of families and communities as well as existing racial differences ${ }^{33-35}$. Research by 
Mkhwanazi (2011) as well as Chohan and Langa (2011) further states that previous studies overlook the social predictors of teenage pregnancy and this inconsideration of the socio-political and structural factors has led to its continued persistence ${ }^{36,37}$. Therefore, it is important to test the influence of household- and community-level factors.

Social disadvantage encompassing poverty and unemployment has plagued sub-Saharan Africa over time. In 2010, an estimated 53 million East Africans were living under the poverty line ${ }^{38}$. This represented more than a third $(38 \%)$ of the region's population. Similarly, in Southern Africa $33 \%$ of people live in severe poverty and in West Africa approximately $36 \%$ of the region's population are poor ${ }^{39,40}$. Unemployment rates are also rather high in these regions ranging from $21 \%$ in East Africa to $40 \%$ in Southern Africa ${ }^{38,39}$. Concerningly, poverty and unemployment have become more common and severe among young people and female-headed households across the sub-continent with dire consequences ${ }^{39}$.

In trying to understand teenage pregnancy, some macro-level theories have been suggested to test the influence of contextual factors in international studies. These include the sociocognitive theory, ecological model as well as the social disorganisation theory. Of these theories, the most studied in sub-Saharan Africa has been social disorganisation at the household-level through family disruption where female single headed households have been proven to consistently predispose teenage females to pregnancy ${ }^{18,31,32}$. In addition, Jelili (2013) examined whether residential density and heterogeneity are predictive of teenage pregnancy in Nigeria and found an association with the former, but not the latter variable $^{29}$. However, other studies have not investigated contextual factors with aid of a relevant theory.

In the present study we examined the applicability of the social disorganisation theory in explaining regional variations in the levels of teenage pregnancy as well as to study the household and community-level factors associated with teenage pregnancy. A regional comparison of teenage pregnancy is valuable in understanding patterns and determinants that are exceptional and to establish where further in-depth studies are necessitated. Therefore, this study aimed to compare the level of teenage pregnancy across different regions of Africa as well as to identify the independent social disorganisation (household and community) predictors of teenage pregnancy in the West, East and Southern regions of sub-Saharan Africa. Two major questions arose in this comparison: What are the levels of teenage pregnancy across SSA regions? and Does social disadvantage play a similar role across regional levels of teenage pregnancy? Answering these questions will increase understanding of the observed patterns of teenage pregnancy in subSaharan Africa.

\section{Theoretical framework}

The study used an adaptation of the social disorganisation theory to explain teenage pregnancy. The social disorganisation theory was developed by Shaw and McKay in 1942 and classically explains the levels of crime in different contexts $^{41,42}$. The theory posits that crime is not randomly distributed occurring equally in all areas, but occurs more frequently in 'bad' neighbourhoods than in 'good' neighbourhoods ${ }^{41}$. The theory has been used to study violence, crime levels, educational behaviour of adolescents and childhood sexual abuse ${ }^{43-46}$.

As applied to this study, this theory holds that the independent variables household-level family disruption, community poverty, and community female unemployment will explain the dependent variable teenage pregnancy because individual behaviour is a construct of the contextual environments that people live in. Deriving from the foregoing theory, the conceptual framework below shows how structural analysis at the household and community level leads to teenage pregnancy. The framework will identify the association between independent variables, social disadvantage and teenage pregnancy in subSaharan Africa.

\section{Methods}

\section{Data source}

Data on teenage pregnancy were compiled for 11 countries from Demographic and Health Surveys 
Figure 1: Conceptual Framework of Association Between Social Disorganisation and Teenage Pregnancy

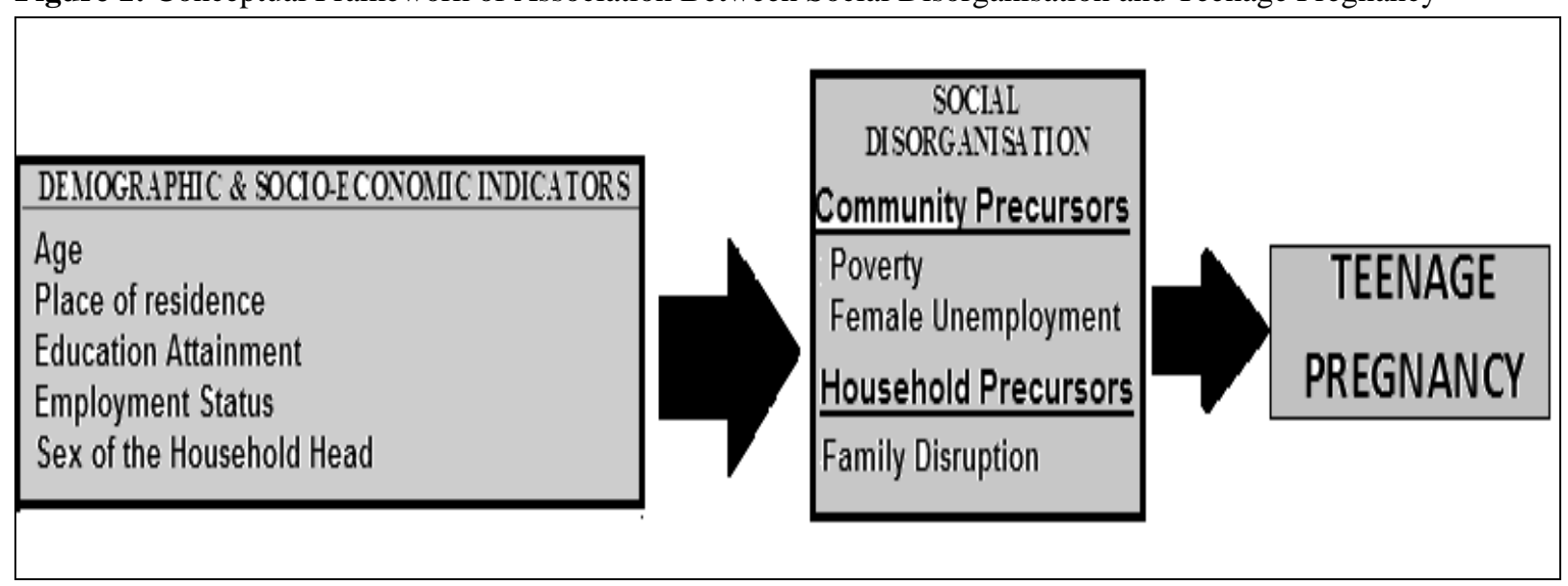

Source: Adapted from Shaw and McKay, 1942

(DHSs). The DHS Program conducts household surveys approximately every five years in various developing countries throughout the world. Its primary aim is to collect and disseminate nationally representative health and population data for monitoring and evaluation of existing policies as well as to aid in the development of new ones. The surveys gather information on fertility, health, mortality and other related issues together with socio-economic and demographic characteristics of individuals.

\section{Country inclusion criteria}

Countries included in the study were all located in sub-Saharan Africa and had three or more DHS surveys conducted between the years 1990 and 2013 with the most recent survey being conducted in or after 2010.

For the purposes of this study countries were divided into regions along traditional geographic boundaries. A total of eleven countries fit this criteria and were included in the study to represent East, Southern and West Africa. The countries were Tanzania, Ethiopia, Rwanda and Uganda from East Africa, Malawi, Mozambique and Zimbabwe from Southern Africa as well as Senegal, Nigeria, Niger and Cote d'Ivoire from West Africa. Only one country from Central Africa (Cameroon) met the above criteria. Therefore, central Africa was omitted from the analysis as not enough countries qualified to represent the region adequately.

\section{Study population}

Females, aged 15 to 19 years old were selected for the analysis. From this group all ever pregnant individuals were compared with those that had never been pregnant at the time of the survey.

\section{Outcome variable}

The outcome variable for this study is ever pregnancy - This included teenage females who were currently pregnant at the time of the survey, those that had one or more children as well as who had ever terminated a pregnancy in the past. All female respondents aged 15-49 were asked questions on current pregnancy status, dates and survival status of all births as well as previous termination of pregnancies. The study considered all females aged 15-19 who answered affirmatively to any of the three areas as the ever pregnant sample and compared them to 15-19 year old girls who had never been pregnant at the time of the survey.

\section{Predictor variables}

The independent variables in this paper encompassed characteristics at the individual level, familial level (household level) and community level. The selection of variables was guided by previous studies and the theoretical foundation. The socio-demographic individual and household level factors included age, place of residence, education attainment, employment 
status and sex of the household head. The social disadvantage factors at household and community levels were family disruption, community level of poverty and community level of female unemployment. Individual and household-level variables were aggregated at the level of the primary sampling unit to generate the communitylevel variables of interest. The variables are clearly shown in Table 1 below.

\section{Statistical analysis}

National levels of teenage pregnancy in the 11 countries included in the study were collected with the aid of StatsCompiler, organised by region namely East Africa, West Africa and Southern
Africa and graphed to show trends in teenage pregnancy levels per region from the years 1992 to 2011. The most recent demographic and health surveys from all included countries were used for descriptive and inferential statistics. Descriptive statistics showed the distribution of respondents as well as ever pregnant teenagers by individual, household and community variables. Values for categorical variables were shown as absolute numbers and percentages while the mean and standard deviations or median and inter-quartile ranges of the continuous variables were recorded depending on normality status. Ranges of the continuous variables were recorded depending on normality status. To establish the predictors of

Table 1: Variable Identification for the Study

\begin{tabular}{|c|c|}
\hline $\begin{array}{l}\text { Variables } \\
\text { Individual and Household Socio-demographic }\end{array}$ & Operational Definition and Coding \\
\hline Age & $\begin{array}{l}\text { Self-reported age of respondent at time of the survey (15, } \\
16,17,18,19)\end{array}$ \\
\hline Place of Residence & Current Place of Residence (Rural, Urban) \\
\hline Education Attainment & $\begin{array}{l}\text { Highest level of education attained (None, Primary, Secondary, } \\
\text { Higher) }\end{array}$ \\
\hline Employment Status & $\begin{array}{l}\text { Employment Status of individual respondent (Employed, } \\
\text { Unemployed) }\end{array}$ \\
\hline Marital Status & Marital Status of respondent (Never Married, Ever Married) \\
\hline Partner's Age & Age of male partner of teenage female: $15-40$ years \\
\hline Sex of Household Head & Sex of the household head (Male, Female) \\
\hline \multicolumn{2}{|c|}{ Household and Community Social Disorganisation } \\
\hline Family Disruption & Single Female Headed Household (Yes, No) \\
\hline Community level of Poverty & $\begin{array}{l}\text { Community poverty percentages into three tertiles (high, medium } \\
\text { and low) }\end{array}$ \\
\hline $\begin{array}{l}\text { Community Percentage } \\
\text { Unemployment }\end{array}$ & $\begin{array}{l}\text { Percentage of unemployed adult females (18 years+) who are } \\
\text { unemployed per PSU }\end{array}$ \\
\hline Community level of Female Unemployment & $\begin{array}{l}\text { Female unemployment percentages divided into four levels (high, } \\
\text { medium, low and none) }\end{array}$ \\
\hline
\end{tabular}

teenage pregnancy, inferential statistical analysis involved correlation testing then multilevel binary logistic regression with a random intercept. Teenage pregnancy was fitted to the models. This is a dichotomous outcome with possible responses of 'yes' or 'no'. Representation of the model is as follows:

$$
\log \left(\frac{\pi_{i j}}{1-\pi_{i j}}\right)=\delta_{0 i j}+\sum_{i j=1}^{\omega} \delta_{i j} z_{i j}+\varepsilon_{i j}
$$

Where: $\pi_{\mathrm{ijk}}=$ probability of having a positive event for the $i^{\text {th }}$ individual in the $\mathrm{j}^{\text {th }}$ community, $\delta \mathrm{s}$ are parameters of the modelzs are regressors, $\varepsilon_{\mathrm{ij}}$ are the residuals model adjusted for individual, household and community level variables yet allowed for heterogeneity between individuals and communities only. Results were presented as odds ratios for ease of interpretation through exponentiation of parameter coefficient estimates. The two-level model established variation between individuals as well as between communities in the risk of the outcome. Simple logistic regression would fail to capture this accurately as members within communities are similar therefore violating the assumption of independence of residuals and underestimating standard errors ${ }^{47-49}$. Teenage pregnancy was regressed on independent variables 
using three models: one for each region in subSaharan Africa. STATA 13.0 was used for data cleaning, storage and all inferential analysis.

\section{Results}

\section{Descriptive outcome}

The general characteristics of the study population are shown in Table 2. Frequency distribution as well as column percentages are given per variable among all participants for each region. Across all three regions fewer teenage females were ever pregnant compared to those that were not. The study population from all three regions had a mean age of 17 years with a standard deviation of two years. Participants were mainly from rural areas in East and Southern Africa yet only a slightly higher proportion was from a rural setting in West Africa. The majority of African teenage females were never married, but West Africa had the largest percentage of ever married females at $30 \%$. The distribution shows that most study participants were attending primary or secondary schooling in all three regions yet the highest levels of teenage females without schooling as well as with secondary school attainment were from West Africa. Most teenage females across Africa were unemployed though a surprisingly high proportion (42\%) of girls from East Africa was employed.

Table 2 shows that most girls were living in households headed by males and in homes without family disruption. The majority of teenage females were from communities with high levels of community poverty and this was greatest in Southern Africa followed by East Africa. Finally, the majority of study participants resided in communities with low levels of female unemployment with West Africa having the most girls from communities with low female unemployment while Southern Africa had the most girls with high levels of community female unemployment.

Levels of teenage pregnancy in sub-Saharan Africa by the three regions are shown in Figure 2. As seen from the graph though Southern Africa began with the lowest levels of teenage pregnancy in 1992, by 2011 it had the highest levels compared to the other two regions. However, this was the opposite occurrence in East Africa where the percentage of teenagers pregnant was the highest in 1992 yet had halved by 2011 to $16.3 \%$. At this point the level of teenage pregnancy was the lowest among all three regions. Finally levels of teenage pregnancy in West Africa had remained fairly constant over time at over $25 \%$. This rendered the region's level of teenage pregnancy to remain in the middle but closely align with that of Southern Africa. Teenage females who had ever been pregnant had an average age of 18 across all regions and were mainly ever married in West $(83 \%)$ and East Africa (65\%) yet mostly never married in Southern Africa. They were also generally unemployed, mostly primary school graduates in East and Southern Africa and living in households without family disruption. Most teenage females that had ever been pregnant regardless of region came from communities with high levels of poverty. Likewise, most girls regardless of region lived in communities with low community levels of female unemployment.

\section{Inferential outcome}

Results of multilevel multivariate logistic regression are shown in Table 3. Certain individual characteristics had similar effects on the likelihood of teenage pregnancy across region such as age, education attainment levels and employment status while others differed by region. Notably as age increased by one year the likelihood of teenage pregnancy more than doubled in all three regions, significantly so. Rural residence increased the likelihood of teenage pregnancy in West Africa and East Africa, while it had no effect in Southern Africa compared to urban residence. Individual respondent's employment increased the likelihood of pregnancy by 15 percentage points in West and Southern Africa while it increased the likelihood by 30 percentage points in East Africa and significantly so. Increasing levels of education attainment were associated with a significant decrease in the average odds of teenage pregnancy in all three regions compared to girls with no education.The sex of household head was uniformly associated with teenage pregnancy across regions. In particular, teenagers from households with female heads had a lower likelihood of teenage pregnancy than those from male headed households. 
Table 2: Distribution of Study Participants by Socio-Demographic and Social Disorganisation Characteristics

\begin{tabular}{|c|c|c|c|}
\hline & West Africa & East Africa & Southern Africa \\
\hline & $\mathrm{n}=15102$ & $\mathrm{n}=11174$ & $\mathrm{n}=10010$ \\
\hline \multicolumn{4}{|c|}{ Ever Pregnant n(\%) } \\
\hline Yes & $3952(26 \%)$ & $1715(15 \%)$ & $3004(30 \%)$ \\
\hline No & $11150(74 \%)$ & $9459(85 \%)$ & $7006(70 \%)$ \\
\hline Age mean; sd & $17 ; 2$ & $17 ; 2$ & $17 ; 2$ \\
\hline \multicolumn{4}{|c|}{ Place of Residence $n(\%)$} \\
\hline Urban & $6633(44 \%)$ & $2527(23 \%)$ & $2841(28 \%)$ \\
\hline Rural & $8469(56 \%)$ & $8647(77 \%)$ & $7169(72 \%)$ \\
\hline \multicolumn{4}{|c|}{ Marital Status n(\%) } \\
\hline Never Married & $10334(70 \%)$ & $9253(89 \%)$ & $3246(95 \%)$ \\
\hline Ever Married & $4350(30 \%)$ & $1157(11 \%)$ & $182(5 \%)$ \\
\hline \multicolumn{4}{|c|}{ Education Attainment n (\%) } \\
\hline None & $5492(36 \%)$ & $1022(9 \%)$ & $530(5 \%)$ \\
\hline Primary & $2578(17 \%)$ & $7515(67 \%)$ & $5852(58 \%)$ \\
\hline Secondary & $6894(46 \%)$ & $2511(23 \%)$ & $3572(36 \%)$ \\
\hline Higher & $136(1 \%)$ & $125(1 \%)$ & $55(1 \%)$ \\
\hline \multicolumn{4}{|c|}{ Employment Status n (\%) } \\
\hline Unemployed & $10954(73 \%)$ & $6497(58 \%)$ & $7199(72 \%)$ \\
\hline Employed & $4072(27 \%)$ & $4649(42 \%)$ & $2803(28 \%)$ \\
\hline \multicolumn{4}{|c|}{ Sex of Household Head n(\%) } \\
\hline Male & $12042(80 \%)$ & $7708(69 \%)$ & $6427(64 \%)$ \\
\hline Female & $3060(20 \%)$ & $3466(31 \%)$ & $3583(36 \%)$ \\
\hline \multicolumn{4}{|c|}{ Family Disruption n (\%) } \\
\hline No & $14989(99 \%)$ & $11005(98 \%)$ & $9863(99 \%)$ \\
\hline Yes & $113(1 \%)$ & $169(2 \%)$ & $147(1 \%)$ \\
\hline \multicolumn{4}{|c|}{ Community Poverty n (\%) } \\
\hline Low & $2342(16 \%)$ & $92(1 \%)$ & $59(0.6 \%)$ \\
\hline Medium & $1794(12 \%)$ & $517(5 \%)$ & $239(2.4 \%)$ \\
\hline High & $10965(73 \%)$ & $10564(95 \%)$ & $9712(97 \%)$ \\
\hline \multicolumn{4}{|c|}{ Community Female Unemployment n (\%) } \\
\hline None & $35(0.2 \%)$ & $415(4 \%)$ & $26(0.3 \%)$ \\
\hline Low & $12219(81 \%)$ & $7950(71 \%)$ & $5482(55 \%)$ \\
\hline Medium & $1282(8 \%)$ & $1205(11 \%)$ & $1908(19 \%)$ \\
\hline High & $1565(10 \%)$ & $1604(14 \%)$ & $2594(26 \%)$ \\
\hline
\end{tabular}

Figure 2: Teenage Pregnancy Levels in sub-Saharan African regions over time, (DHS: 1992-2011).

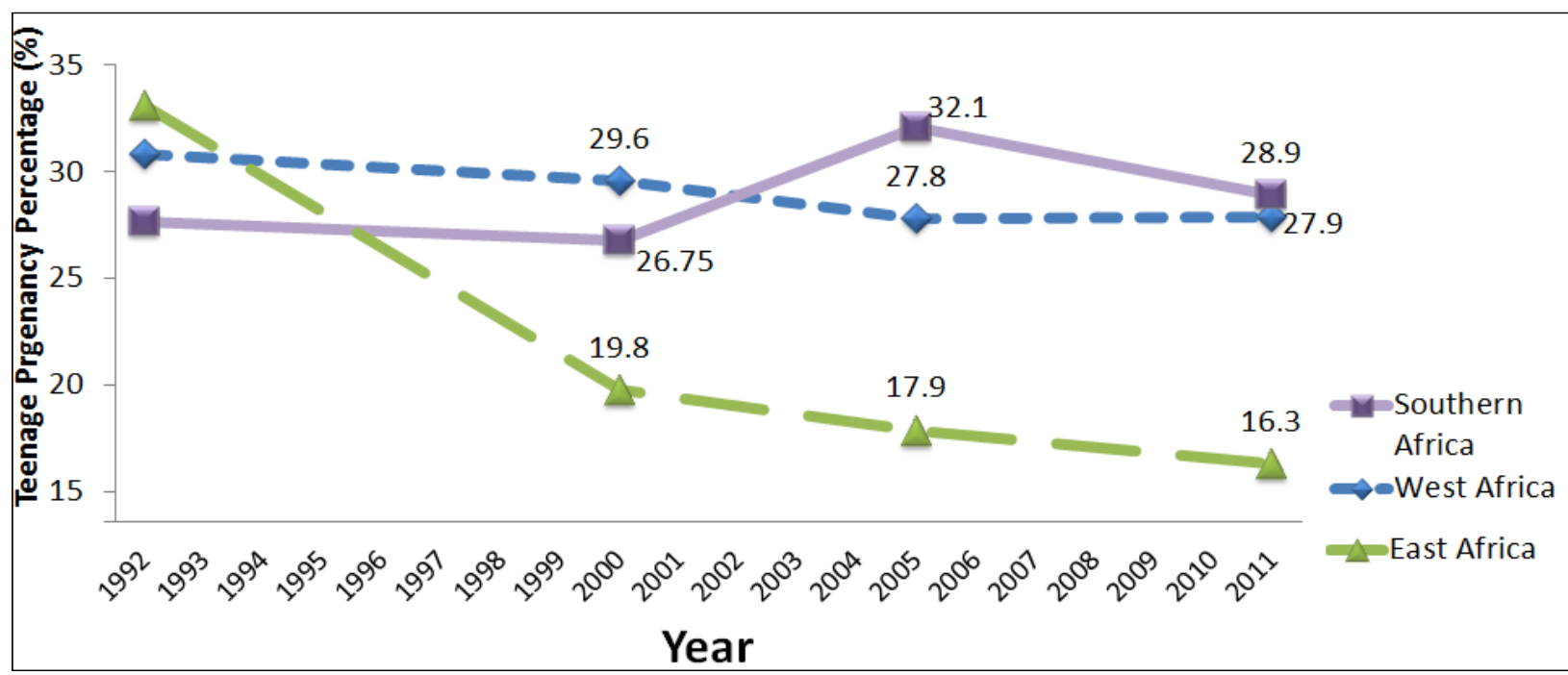

Source: Author computation from DHS, StatsCompiler 
Table 3: Multilevel Adjusted Logistic Regression of Ever Pregnant Teenage Females by SSA Region

\begin{tabular}{|c|c|c|c|c|c|c|}
\hline & \multicolumn{2}{|c|}{ West Africa } & \multicolumn{2}{|c|}{ East Africa } & \multicolumn{2}{|c|}{ Southern Africa } \\
\hline & OR & SE & OR & SE & OR & SE \\
\hline Age & $2.30 *$ & 0.020 & $2.61 *$ & 0.031 & $2.48 *$ & 0.022 \\
\hline Urban residence (RC) & 1 & & 1 & & 1 & \\
\hline Rural residence & $2.30 *$ & 0.065 & 1.18 & 0.118 & 0.99 & 0.075 \\
\hline No education (RC) & 1 & & 1 & & 1 & \\
\hline Primary education & $0.71 *$ & 0.065 & $0.42 *$ & 0.106 & $0.75^{*}$ & 0.126 \\
\hline Secondary education & $0.15^{*}$ & 0.067 & $0.13^{*}$ & 0.140 & $0.26^{*}$ & 0.134 \\
\hline Higher education & $0.02 *$ & 0.501 & $0.04 *$ & 0.568 & $0.02 *$ & 0.737 \\
\hline Unemployed (RC) & 1 & & 1 & & 1 & \\
\hline Employed & $1.15^{*}$ & 0.057 & $1.31 *$ & 0.084 & $1.15^{*}$ & 0.063 \\
\hline Male Head of Household (RC) & 1 & & 1 & & 1 & \\
\hline Female Head of Household & $0.73 *$ & 0.068 & $0.69 *$ & 0.082 & $0.79 *$ & 0.057 \\
\hline No Family Disruption (RC) & 1 & & 1 & & 1 & \\
\hline Family Disruption & 1.01 & 0.313 & $0.40 *$ & 0.365 & $0.39 *$ & 0.257 \\
\hline Comm. Female Unemployment (\%) & 1.00 & 0.002 & $0.99 *$ & 0.003 & $1.01 *$ & 0.002 \\
\hline Community Poverty Percentage (\%) & $1.01 *$ & 0.002 & $1.02 *$ & 0.005 & $1.01 *$ & 0.003 \\
\hline
\end{tabular}

Abbreviation: -OR: Odds ratio, SE: standard error, RC: reference category, ${ }^{*} \mathrm{p}<0.05$

With respect to social disorganization, related characteristics regions displayed different associations except in the area of community levels of poverty which was consistently and statistically significantly associated with a higher likelihood of teenage pregnancy across regions. In particular, with every increased percentage in the community level of poverty, the likelihood of teenage pregnancy also increased by one percent in West and Southern Africa and by 2 percentage points in East Africa. Surprisingly, family disruption decreased the odds of pregnancy in both East and Southern Africa while it had no effect on teenage pregnancy in West Africa. The odds of pregnancy increased as community levels of female unemployment increased in Southern Africa with the likelihood of teenage pregnancy increasing by one percentage point for every $1 \%$ increase in the level of female unemployment and decreased the odds of teenage pregnancy in East Africa by one percentage point for every $1 \%$ increase in the level of community female unemployment, but had no effect in West Africa.

\section{Discussion}

In this study, we examined whether social disadvantage at household and community levels were associated with teenage pregnancy in selected African countries. Using the theory of social disorganisation, we argue that teen pregnancy is likely to be associated with social disadvantage at household and community levels.
This means that teenage pregnancy is likely to occur in household and community social disadvantage.

\section{West Africa}

Results showed that teenage pregnancy levels in West Africa had consistently remained high above $25 \%$ over the period 1992 to 2011 . The prevalence of teenage pregnancy in 2011 had stagnated at $27.9 \%$ and this was possibly associated with a number of factors. The report on world fertility levels and trends corresponds with this finding ${ }^{50}$. It showed very little change in the adolescent fertility rates of many countries in Africa including Niger from 1990 to 2010 as progress in the decline of adolescent fertility had been very slow. Possible reasons for the plateauing of teenage pregnancy at the high level of above $25 \%$ and the associations found include culture and religion which increase the value of marriage and patriarchy in this region $^{51}$.

The community-level of poverty was the only social disadvantage factor found to be independently associated with teenage pregnancy in West Africa. Multilevel regression showed that for every percentage increase in community levels of poverty, the likelihood of teenage pregnancy significantly increased by $1 \%$. A number of international and regional studies found similar results.

The global study by Blum et al (2013) aimed to present the social determinants of 
adolescent pregnancy through the review of previous literature and found that at community level neighbourhood deprivation as well as poverty increased the likelihood of adolescent pregnancy $^{52}$. Likewise, the longitudinal study conducted by Meade et al (2008) followed up girls from early adolescence for six years and found poverty to be among the strongest factors associated with teenage pregnancy ${ }^{53}$. Turning to studies in sub-Saharan Africa, poverty levels have been previously researched at the individual-level not at community-level. For example, the descriptive study conducted in Nigeria by Isa et al (2009) aimed to establish the socio-demographic determinants of teenage pregnancy using hospital records $^{26}$. The study found that most 14 to 19 year old girls who had been pregnant were from a low social class. Finally, the multi-country study by Palermo and Peterman (2009) investigated teenage pregnancy in ten African countries over the time period 2003 to $2006^{26}$. The study revealed that low socio-economic status was associated with teenage pregnancy across all the countries.

Consequently, this study goes further to show that it is not only the status of individuals that poses a risk to getting pregnant while a teenager, but the contextual environment in which one is in as well. Reasons for the association of community-levels of poverty and an increased risk of teenage pregnancy may be related to such areas being rural areas. These residential zones are commonly associated with greater adherence to culture and traditional beliefs which may exacerbate levels of child marriage. Child marriage in poor settings is justified as a means of lowering the economic burden within the household through marrying off female children that decreases the household size as well as increasing provision through the dowry obtained from the groom upon marriage ${ }^{54}$. To this end, an urgent need for the awareness of risks associated with child marriage leading to a total abolishment of the phenomenon is seen in West Africa.

\section{East Africa}

In East Africa results showed that teenage pregnancy levels had decreased consistently first rapidly then at a slower pace from the year 2000 . This had led to the 2011 prevalence of teenage pregnancy being approximately half of what it was in 1991 constituting the greatest decrease in teenage pregnancy among the three regions. The study by Harwood-Lejeune (2001) suggested a similar pattern in declining adolescent fertility in East Africa as this study's findings ${ }^{55}$. Explanations given for this included a rising age of marriage as well as age at first birth leading to lower levels of premarital teenage childbearing.

Family disruption and community female unemployment levels were inversely related to teenage pregnancy in East Africa. The study by Nyakubega (2010) found high levels of awareness of contraceptives among Tanzanian adolescents ${ }^{24}$. Additionally, the greatest source of information was said to be from parents and health centres at $82.6 \%$ followed by school and finally peers. It is possible that the various programmes initiated to decrease HIV and AIDS in East Africa have influenced learners as well as their parents positively. In single parented households, communication on reproductive health matters with children may be increased as a method to hopefully dissuade them from risky sexual behaviour. Nevertheless, the provision of education in boarding facilities may also be protective for girls as they are less exposed to the opposite sex and are brought up in a safe environment where teachers can engage, influence and keep an eye on developing teenagers more often.

However, community poverty was positively and significantly associated with teenage pregnancy in East Africa. This finding was not surprising as some local previous studies have hinted at this though having used poverty data at the individual or household level. In particular, the study by Were (2007) investigated determinants of teenage pregnancy in Kenya and concluded that overall widespread poverty predisposed young females to teenage pregnancy $^{28}$. Therefore, the author suggested the need to study teenage pregnancy in light of the broader socio-cultural and socio-economic environment that adolescents resided in. Still, three other studies conducted in various countries of East Africa found higher socio-economic status to be strongly associated with a delayed transition to pregnancy ${ }^{20,34,56}$. 
In addition, numerous international studies have attested to this being the case ${ }^{57,58}$. In particular the studies show that neighbourhoods characterised by poverty have higher levels of teenage pregnancy as teens living in poor communities with less opportunities are more likely to engage in sex at earlier ages and to eventually become pregnant. Additionally, in localities where poverty is rife young people may also turn to transactional sex as an economic survival strategy with pregnancy resulting if contraception fails or is unemployed ${ }^{59}$. Therefore, it is paramount that quality levels of education continue being advocated more vigorously especially in poor settings where government schooling prevails to equip young women with greater levels of agency, choice and empowerment to decide on their own future.

\section{Southern Africa}

Teenage pregnancy levels in Southern Africa were initially the lowest among the three regions at approximately $27 \%$ in 1992 . This level remained consistent until the year 2000 when it began to rise reaching a peak of $32.1 \%$ in 2005 . From here, the prevalence of teenage pregnancy decreased slightly to $28.9 \%$ where it settled as the highest prevalence among the three regions. Southern Africa is classically known as the region with the lowest levels of adolescent fertility as well as fertility in sub-Saharan Africa.

However, this study demarcated regions based on geographical borders and included only three countries to represent Southern Africa. Two of these countries namely, Malawi and Mozambique have been shown to have high rates of adolescent births in previous studies ${ }^{3,4}$. Additionally, other past studies have found other Southern African countries such as Zambia and Namibia to have higher levels of premarital childbearing than some West African countries $^{60,61}$. This shows that differences can occur in levels of teenage pregnancy not only across, but even within regions.

Family disruption was significantly protective against teenage pregnancy in Southern Africa. The study by Speldnaes (2013) highlights the vast differences in the conceptualisation of motherhood and fatherhood in the Southern
African region where the former is associated with responsibility and sacrificial caring for children single-handedly so if needs be despite the circumstances $^{62}$. Consequently, young females growing up with single mothers would be more conscientised of the various sacrifices accompanying being a single parent. This may dissuade them from predisposing themselves to situations that would result in early childbirth. Closely related to this, single mothers may desire their children to avoid their own regrets of the past and thereby repeatedly encourage them to pursue educational paths and other constructive endeavours in order to ensure a better future than their own.

Additionally, single mothers may raise their daughters to be more aware of the negative repercussions of early childbirth due to having been through the experience themselves. Previous literature has shown the importance of motherdaughter communication in being able to delay and limit sexual activity as well as increase levels of contraception and other forms of protection during intercourse among adolescents ${ }^{63}$. Additionally, higher levels of maternal understanding, openness and reasoning regarding sexual matters have been shown to dissuade sexual activity as well as influence the intentions of youngsters to delay sexual intercourse to later years ${ }^{64}$. This shows the importance of creating teenage pregnancy intervention strategies that incorporate parents to equip them to freely communicate with their children about sexual issues.

For every percentage increase in community female unemployment and community poverty the likelihood of teenage pregnancy increased by one percentage point. These factors may be closely associated as poorer communities would have higher levels of female unemployment due to decreased levels of community resources and opportunities. This association was clearly seen upon cross-tabulating the community levels of female unemployment by community levels of poverty as all the ever pregnant female teenagers from communities with high community levels of female unemployment were from the poorest communities while all pregnant teenagers from 
communities with low poverty were also from communities with low levels of community female unemployment.

Additionally, a greater proportion of teenage females from communities with medium levels of community poverty had low or medium levels of female unemployment. Therefore, the degree of community levels of female unemployment correlated with the levels of poverty in communities. Communities which had high levels of female unemployment and poverty would also predispose women, both young and old, to engage in transactional sex. The engagement of older women in this practice might actually increase its frequency among younger generations as it would then be considered socially acceptable due to it being common. Additionally, in the absence of contraceptive use among younger females transactional sex would increase the likelihood for sexually transmitted infections as well as early childbearing. As a result it is necessary to improve levels of development within communities throughout Africa to ensure a decrease in poverty, unemployment as well as teenage pregnancy as shown in this study.

The following limitations should be considered while interpreting the findings of this study. First, the quality of individual and household-level social disadvantage-related and socioeconomic indicators were reliant on the underlying datasets as this was a secondary analysis of demographic and health survey data. Other important community-level characteristics such as socio-political and cultural issues were not covered as they were unavailable in the datasets. This may have possibly influenced the differences in teenage pregnancy across communities in the various regions of sub-Saharan Africa. The crosssectional nature of this study also rendered it impossible to determine the temporal order of teenage pregnancy and social disadvantage factors. Therefore, the relationships established in the study merely indicate association between the variables and not causality. Nevertheless, the use of this cross-sectional data is useful as a primary step in testing the possible link between teenage pregnancy and social disadvantage statistically.

\section{Conclusion}

This study has shown the vast differences in teenage pregnancy across sub-Saharan Africa. These differences span from the trends in teenage pregnancy prevalence to the various social disadvantage-related determinants of teenage pregnancy on the sub-continent. Taken together, our findings suggest the importance of understanding the influence of social disadvantage on pregnancy among teenage females in subSaharan Africa. It is important to note that subSaharan African regions are not homogenous yet all battle with community-level inequality that leads to reproductive health disparities among young females. Social disadvantage factors at household level influence the likelihood of teenage pregnancy differently in the various regions of the sub-continent due to the regional mechanisms in place to raise the girl child as well as to address the phenomenon of early pregnancy. These fundamentals are important to consider in implementing specific interventions that would address teenage pregnancy throughout the subcontinent uniquely yet appropriately. Therefore, it is hoped that this study will be utilised to guide the process of acquiring region-specific interventions to decrease the levels of unintended teenage pregnancy in sub-Saharan Africa.

In conclusion, our findings support the usefulness of the social disorganisation theory in understanding African sexual and reproductive health dynamics and show how social disadvantage characterised by community conditions may play a role in teenage pregnancy among female adolescents. Our findings also suggest the need for teenage pregnancy intervention programmes to address multilevel factors such as family disruption as well as the need for governments to address issues of unemployment, poverty and inequality. Until these are addressed, focusing only on individual factors will not be sufficient to address the challenge of teenage pregnancy and its consequences in sub- 


\section{Saharan Africa.}

\section{Acknowledgements}

An earlier version of this paper was presented at the Population Association of America Annual Meeting held in San Diego, USA from the $30^{\text {th }}$ of April to the $2^{\text {nd }}$ of May 2015. Astute comments from conference participants are gratefully acknowledged. Additionally, the authors would like to thank Measure DHS for providing them with data from Senegal, Nigeria, Niger, Ivory Coast, Tanzania, Ethiopia, Rwanda, Uganda, Malawi, Mozambique and Zimbabwe for this study.

\section{References}

1. United Nations Population Fund. Motherhood in Childhood: Facing the challenge of adolescent pregnancy. New York: UNFPA, 2013.

2. World Health Organization. Adolescent Pregnancy. Secondary Adolescent Pregnancy 2014. http://www .who.int/maternal_child_adolescent/topics /maternal/adolescent_pregnancy/en/.

3. Clifton D, Hervish A. The World's Youth 2013 Data Sheet. Washington DC: Population Reference Bureau 2013.

4. Loaiza E, Liang M. Adolescent Pregnancy: A Review of Evidence. New York: United Nations Population Fund, 2013.

5. Macleod CI, Tracey T. A decade later: follow-up review of South African research on the consequences of and contributory factors in teen-aged pregnancy. South African Journal of Psychology 2010; 40(1):18-31.

6. Mangiaterra V, Pendose R, McClure K, et al. Adolescent Pregnancy. In: Heine M, ed. Making Pregnancy Safer Notes. Geneva: World Health Organisation, 2008:4.

7. Tsui A, Creanga A, Ahmed S. The role of delayed childbearing in the prevention of obstetric fistulas. International Journal of Gynecology \& Obstetrics 2007;99:S98-S107.

8. Lee D. The early socioeconomic effects of teenage childbearing: A propensity score matching approach. Demographic Research 2010;23(25):697736.

9. Chen X-K, Wen SW, Fleming N, et al. Teenage pregnancy and adverse birth outcomes: a large population based retrospective cohort study. International Journal of Epidemiology 2007; 36(2):368-73.

10. Hoque M, Hoque E, Anwar M, et al. Assessment and Comparison of Obstetric Characteristics and Perinatal Outcomes of Rural Population of South
Africa. Tropical Journal of Obstetrics and Gynaecology 2013;26(1):60-67.

11. Reynolds HW, Wong EL, Tucker H. Adolescents' use of maternal and child health services in developing countries. International family planning perspectives 2006;32(1).

12. Organization $\mathrm{WH}$. WHO guidelines on preventing early pregnancy and poor reproductive health outcomes among adolescents in developing countries. 2011.

13. Duflo E, Dupas P, Kremer M. Education, HIV, and early fertility: Experimental evidence from Kenya: National Bureau of Economic Research, 2014.

14. Tombros A. Integrating efforts to prevent HIV other STIs and pregnancy among teens in developing countries: three case studies. 2005.

15. Neal SE, Chandra-Mouli V, Chou D. Adolescent first births in East Africa: disaggregating characteristics, trends and determinants. Reproductive health 2015;12(1):13.

16. Amoran OE. A comparative analysis of predictors of teenage pregnancy and its prevention in a rural town in Western Nigeria. International journal for equity in health 2012;11(1):1-7.

17. Demissie T. Levels, trends and differentials of adolescent motherhood in Ethiopia. Addis Ababa University, 2008.

18. Francis GF. The effect of household characteristics on adolescent childbearing in Lesotho. University of the Witwatersrand, 2008.

19. Isa AI, Gani IOO. Socio-demographic determinants of teenage pregnancy in the Niger Delta of Nigeria. Open Journal of Obstetrics and Gynecology 2012;2:239.

20. Kaphagawani N. Risk factors for unwanted/ unplanned teenage pregnancy in Zomba District, Malawi. University of the Witwatersrand, 2006.

21. Kyokwijuka MBG. Risk Factors of Adolescent Pregnancy in Kabale District-Uganda. Makere University, 2009.

22. Molosiwa S, Moswela B. Girl-pupil dropout in secondary schools in Botswana: Influencing factors, prevalence and consequences. International Journal of Business and Social Science 2012;3(7):265-71.

23. Nwogwugwu NC. Socio-demographic determinants of adolscent fertility in Zambia. University of the Witwatersrand, 2013.

24. Nyakubega P. Factors associated with adolescent pregnancies among secondary school students. a study from Tanga-Tanzania. Dar Es Salaam Medical Students' Journal 2010;16(1):31-34.

25. Ogunlesi T, Ayeni V, Jagun E, et al. Socio-clinical factors related to the perinatal outcome of teenage pregnancies in a Nigerian teaching hospital. Nigerian Journal of Paediatrics 2013;40(3):290-94.

26. Palermo T, Peterman A. Are Female Orphans at Risk for Early Marriage, Early Sexual Debut, and Teen Pregnancy? Evidence from Sub-Saharan Africa. Studies in Family Planning 2009;40(2):101-12.

27. Runsewe-Abiodun TI, Bondi SF. Teenage pregnancy and 
implications on child survival amongst mothers attending a clinic in the East-End, Freetown, Sierra Leone. Open Journal of Pediatrics 2013;3:294.

28. Were M. Determinants of teenage pregnancies: The case of Busia District in Kenya. Economics \& Human Biology 2007;5(2):322-39.

29. Jelili M, Akindele O, Akintayo O. Teenage Pregnancy and Home Environment Factors in Ogbomoso, Nigeria. Research on Humanities and Social Sciences 2013;3(18):69-77.

30. Magadi MA, Agwanda AO. Determinants of transitions to first sexual intercourse, marriage and pregnancy among female adolescents: Evidence from South Nyanza, Kenya. Journal of Biological Sciences 2009(41):409-27.

31. Oyefara JL. Determinants of adolescent fertility in contemporary Yoruba society: a multivariate analysis. Gender and Behaviour 2011;9(2):39794004.

32. Ugoji F. Parental marital status and peer influence as corelates of teenage pregnancy among female teens in south-South Nigeria. Gender and Behaviour 2011;9(2):4125-38.

33. Jewkes R, Morrell R, Christofides N. Empowering teenagers to prevent pregnancy: lessons from South Africa. Culture, Health \& Sexuality 2009;11 (7): 675-88.

34. Mkhwanazi N. Understanding teenage pregnancy in a post-apartheid South African township. Culture, Health \& Sexuality 2010;12(4):347-58.

35. Panday S, UNICEF. Teenage Pregnancy in South Africa: With a Specific Focus on School-going Learners: Executive Summary: Department of Basic Education, 2009.

36. Chohan Z, Langa M. Teenage mothers talk about their experience of teenage motherhood. Agenda 2011;25(3):87-95.

37. Mkhwanazi N. Developing and expanding our ideas about teenage desire and fertility. Agenda 2011;25(3):2-8.

38. Eyakuze A, Salim A. The state of East Africa 2012: Deepening integration, intensifying challenges: Society for International Development, Regional Office for Eastern Africa, 2012.

39. Open Society Initiative for Southern Africa. Inequality in Southern Africa:Options for Redress. South Africa: OSISA, 2011.

40. StatsCompiler. SatsCompiler Computations. In: Survey DaH, ed., 2015.

41. Kubrin C. Social Disorganization Theory: Then, Now and in the Future. In: Krohn, ed. Handbook on Crime and Deviance: Springer Scince and Business Media, 2009.

42. Shaw CR, McKay HD. Juvenile delinquency and urban areas: A study of rates of delinquents in relation to differential characteristics of local communities in American cities: University of Chicago Press Chicago, 1942.

43. Bowen NK, Bowen GL, Ware WB. Neighborhood Social
Disorganization, Families, and the Educational Behavior of Adolescents. Journal of Adolescent Research 2002;17(5):468-90.

44. McNulty TL, Bellair PE. Explaining Racial And Ethnic Differences In Serious Adolescent Violent Behavior*. Criminology 2003;41(3):709-47.

45. Tolan PH, Gorman-Smith D, Henry DB. The developmental ecology of urban males' youth violence. Developmental psychology 2003; 39(2): 274.

46. Yahaya I, Uthman O, Soares J, et al. Social Disorganization and history of child sexual abuse against girls in sub-Saharan Africa: a multilevel analysis. BMC International Health and Human Rights 2013;13(33):8.

47. Kawachi I, Subramanian SV. Neighbourhood influences on health. Journal of Epidemiology and Community Health 2007;61(1):3-4.

48. Merlo J. Multilevel analytical approaches in social epidemiology: measures of health variation compared with traditional measures of association. Journal of epidemiology and community health 2003;57(8):550-52.

49. Subramanian S. The relevance of multilevel statistical methods for identifying causal neighborhood effects. Social science \& medicine 2004;58 (10):1961-67.

50. United Nations. Fertility Levels and Trends as Assessed in the 2012 Revision of the World Population Prospects. New York: United Nations, 2013.

51. Walker J-A. Early Marriage in Africa-Trends, Harmful Effects and Interventions. African journal of reproductive health 2012;16(2):231-40.

52. Blum R, John Hopkins Bloomberg School of Public Health. A Global Look at Adolescent Pregnancy Prevention: Strategies for Success. In: Office of Adolescent Health, ed. Webcast. Washington, DC: US Department of Health and Human Services, 2013.

53. Meade CS, Kershaw TS, Ickovics JR. The intergenerational cycle of teenage motherhood: an ecological approach. Health Psychology 2008;27 (4):419.

54. Walker J-A. Why Ending Child Marriage Needs to Be an Education Goal. Improving Learning Opportunities and Outcomes for Girls in Africa 2013:6.

55. Harwood-Lejeune A. Rising age at marriage and fertility in Southern and Eastern Africa. European Journal of Population/Revue Européenne de Démographie 2001;17(3):261-80.

56. Nalenga GZ. Causes of unintended pregnancy among adolescents in Addis Abeba, Ethiopia. 2012.

57. Kirby D. Antecedents of adolescent initiation of sex, contraceptive use, and pregnancy. American Journal of Health Behavior 2002;26(6):473-85.

58. Miller BC. Family influences on adolescent sexual and contraceptive behavior. Journal of Sex Research 2002;39(1):22-26.

59. Leclerc-Madlala S. Transactional sex and the pursuit of 
modernity. Social dynamics 2003;29(2):213-33

60. Palamuleni M, Adebowale A. Patterns of premarital childbearing among unmarried female youths in sub-Saharan Africa: Evidence from demographic health survey. Scientific Research and Essays 2014;9(10):421-30.

61. Tawiah E. Adolescent fertility and reproductive health in four sub-Saharan African countries. 2002.

62. Spjeldnæs IO. Family values of young people in Limpopo, South Africa: A sociocultural psychological study on perceptions and experiences of reproduction and parenthood. 2013.

63. Hutchinson MK, Jemmott JB, Jemmott LS, et al. The role of mother-daughter sexual risk communication in reducing sexual risk behaviors among urban adolescent females: a prospective study. Journal of adolescent health 2003;33(2):98-107.

64. Fasula AM, Miller KS. African-American and Hispanic adolescents' intentions to delay first intercourse: Parental communication as a buffer for sexually active peers. Journal of Adolescent Health 2006;38(3):193-200. 